\title{
Computer Aided Quick Determination of Earthquake Performance of Buildings by Using Street Survey and Preliminary Assessment Methods
}

\author{
${ }^{1}$ Murat Muvafik and ${ }^{* 2}$ Muhammet Özdemir \\ ${ }^{1}$ Faculty of Engineering, Department of Civil Engineering Van Yüzüncü Yıll University, Turkey \\ *2 Faculty of Engineering, Department of Civil Engineering Erzurum Technical University, Turkey
}

\begin{abstract}
In this study, 7 different rapid evaluation methods which are used to determine the performance of buildings under the influence of earthquakes in a fast and practical way are examined. These methods were used to determine the earthquake performance behaviors (risky or safe) of buildings according to each method by using the parameters of 50 buildings that were collapsed or severely damaged in Van earthquake that occurred in 2011. Accurate estimation percentages of the methods on the buildings were calculated by comparing the obtained earthquake performance behaviors with the current situation of the buildings. The most suitable method has been tried to determine for 50 buildings related to these calculations. At the same time, a computer program called EPA (Earthquake Performance Analysis) was developed in order to evaluate the parameters of the related data set faster, easier and without error.

Three of the 7 rapid assessment methods used to determine the earthquake performance behavior of buildings are first-stage methods called street screening (6306 RYY, FEMA P-154 and Sucuoğlu and Yazgan level-1), and the remaining four methods are second-stage methods called pre-assessment (Sucuoğlu and Yazgan level-2, Özcebe, Yakut and MVP). According to the results, the pre-assessment methods predicted the earthquake performance status of the buildings examined by $24 \%$ higher than the street screening methods. At the same time, the most successful method of street survey methods was 6306 RYY with 74\% accurate estimation, and the most successful method of preliminary assessment with $86 \%$ accurate prediction was Yakut method.
\end{abstract}

Key words: Damage score, Earthquake performance, Rapid assessment methods, Reinforced concrete buildings

\section{Introduction}

Since the existence of the Earth, earthquakes have been occurring all over the world due to the movement of the earth's crust. In one of the countries most affected by the earthquake, Turkey, located on the Alpine-Himalayan earthquake zone, which is one of the active earthquake zones, Turkey has been affected by large earthquakes in which thousands of lives and millions of dollars were lost in the past. According to the Earthquake Zones Map, 92\% of the country is in earthquake zones and $95 \%$ of the country's population lives under earthquake hazard [1]. Between the years 1903-2014 119 earthquake in the range of $M=6.0-11.0$ magnitude occurred in Turkey. These earthquakes resulted in an average annual loss of 748 lives, 5291 damaged buildings and 721,610 US Dollars. These results clearly show the effect of earthquakes that may occur naturally and

\footnotetext{
${ }^{*}$ Corresponding author: Muhammet Özdemir Address: Faculty of Engineering and Architecture, Department of Civil Engineering Erzurum Technical University, 54187, Erzurum TURKEY.

E-mail address: muhammet.ozdemir22@erzurum.edu.tr, Phone: +905343697981
} 
inevitably, unless the necessary measures are taken [2].

Experience and statistics have shown the importance of determining the behavior of buildings under earthquake impact. Therefore, many studies have been carried out to determine the behavior of buildings under earthquake effects and these studies have been classified into three categories. These categories can be listed as street survey methods (SSM), preliminary assessment methods (PAM) and detailed analyzes. Street survey methods are quite simple and fast. In this method, some parameters such as number of stories, irregularity information, and structural system are obtained by making observations from outside without entering the building and then performance of the building against the earthquake effect is determined. PAM, which is another method, includes some different parameters which should be taken from the inside the building (material information, structural system element dimensions, etc.) in addition to the parameters used in SSM. Although this method (PAM) takes a little longer time than SSM, accuracy ratio is higher. The third and the last method used to determine earthquake performance is detailed analysis. This method determines the performance of buildings against earthquake effects by performing linear and nonlinear analyzes. Although this method is highly accurate, it takes much longer time. When considering the need of determining earthquake performance of thousands of buildings, the importance of rapid determination can be easily understood. For this reason, researchers have done many studies on SSM and PAM methods, which are called rapid assessment methods. The main purpose of these methods (SSM and PAM) is to determine the buildings that need detailed analysis and to determine the distribution of the risky buildings.

This study aims two main goals. The first is to develop a computer program that can determine the earthquake performance status of buildings in a much shorter time and to reduce error that the human may causes. The secondly, by selecting the most common 7 of the existing many rapid assessment methods ( 3 of them SSM and 4 of them PMA), it is to evaluate these methods according to the parameters of 50 buildings that have collapsed or severe damage in the earthquake in Van in 2011 and is to find the most suitable method for these buildings.

In this context, the parameters of 50 buildings were transferred to the developed EPA (Earthquake Performance Analysis) program and the earthquake performance status (risky or safe) of the buildings were determined according to the 7 rapid assessment methods selected. At the same time, earthquake performance graphs, earthquake performance maps and earthquake performance reports of all buildings were also created within the EPA program.

\section{Materials and Method}

In this chapter, the details of the 7 rapid evaluation methods examined in the study, the parameters used in these methods, the effects of the parameters on the earthquake performance of buildings and the details of the developed EPA computer program are explained.

\subsection{Parameters used in methods}


Rapid assessment methods have many different parameters that can significantly affect the earthquake performance of buildings such as architectural, structural system, soil class, and earthquake zone of the region where they are created. While some of these parameters are used in almost all rapid assessment methods, some parameters are important for several methods. These parameters can be classified under 5 main headings. These parameters include structural parameters resulting from the structural features of the building, the ground parameters resulting from the ground where the buildings are located, the earthquake parameters resulting from the seismicity status of the buildings, the irregularity parameters resulting from the irregularities of the building and the other factors that affect the buildings.

Table 1. Parameters used in rapid assessment methods

\begin{tabular}{|c|c|c|c|c|}
\hline Structural Parameters & $\begin{array}{l}\text { Irregularity } \\
\text { Parameters }\end{array}$ & Ground Parameters & Earthquake Parameters & Other Parameters \\
\hline Number of stories & Soft story & Local soil conditions & $\begin{array}{l}\text { *Sds (Design spectral } \\
\text { acceleration factor) }\end{array}$ & Year of construction \\
\hline $\begin{array}{l}\text { Structural system type } \\
\text { (Frame or frame and } \\
\text { shear walls) }\end{array}$ & Short column & Topographic effects & & Post-Benchmark \\
\hline Pounding & Plan Irregularity & $\begin{array}{l}\text { *Peak Ground } \\
\text { Velocity (PGV) }\end{array}$ & & $\begin{array}{l}\text { Material properties } \\
\text { (steel and concrete) }\end{array}$ \\
\hline $\begin{array}{l}\text { Apparent building } \\
\text { quality }\end{array}$ & Vertical Irregularity & & & \\
\hline $\begin{array}{l}\text { *Redundancy (Frame } \\
\text { Irregularity) }\end{array}$ & $\begin{array}{l}\text { Heavy Overhangs } \\
\text { (like balconies) }\end{array}$ & & & \\
\hline \multicolumn{5}{|l|}{ Ground floor area } \\
\hline $\begin{array}{c}\text { Size of vertical } \\
\text { members (column and } \\
\text { shear wall) }\end{array}$ & & & & \\
\hline
\end{tabular}

Redundancy (Frame Irregularity): When the number of continuous frames, or number of bays in a building system is insufficient, lateral loads may not be distributed evenly to frame members. Especially those frames exhibiting inelastic response during earthquakes suffer from lack of sufficient redundancy, which leads to localized heavy damages [3].

Peak Ground Velocity: PGV, which is called the maximum ground velocity, is the velocity of the earthquake waves on the ground along with the fault breaking during the earthquake. This speed varies according to ground characteristics. While the velocity increases on a soft ground, the earthquake waves are damped on hard soils and the velocity decreases.

Design spectral acceleration factor $(S d s)$ : This factor, which emerging with the updated earthquake regulation (Principles for Designing Buildings under Earthquake Impact, 2018), is used to determine the earthquake hazard zone together with the ground class. Increasing this factor, increases the effect of the earthquake force that will affect the building. This value can be selected directly via Turkey Earthquake Hazard Maps-Interactive Web Applications (http://tdth.afad.gov.tr). 


\subsection{Methods}

This study does not provide a new rapid assessment method for determining the earthquake performance of buildings. This study presents a computer program which combines seven different rapid evaluation methods under one roof and provides a comparison of these methods in computer program. Therefore, it is important to understand these 7 rapid assessment methods. Without giving details of the methods, only the names of the methods, basic application steps and references are given.

\subsubsection{Street survey methods (First Level Methods)}

1. FEMA P-154 (Rapid Visual Screening of Buildings for Potential Seismic Hazards) [4]

2. PRINCIPLES FOR DETERMINATION OF RISK STRUCTURES / Simplified Methods for Determining Regional Earthquake Risk Distribution of Buildings [5]

3. Simple Survey Procedures for Seismic Risk Assessment in Urban Building Stocks (Level1) [6]

\section{$\underline{\text { Features }}$}

These methods are the most practical methods used to determine the earthquake performance of buildings.

The number of parameters of these methods is less than that of other earthquake performance determination methods. As a result, accuracy ratio of methods is also lower.

The main purpose of the method is to calculate the performance of the building against the earthquake force by observing from outside without entering the building whose performance will be determined.

$\rightarrow$ The basis of the method depends on statistical data.

After earthquakes, the researchers go to the region to examine the state of the buildings and correlate the performance of the earthquake with the parameters of the building (short column, heavy overhangs, soft stories, etc.).

As a result of statistical studies, the importance of related parameters is determined. Scores are given to the parameters of buildings according to these grades. Afterwards, earthquake performance formulas are developed by establishing relationships between these scores.

\subsubsection{Preliminary assessment methods (Second Level Methods)}

1. Simple Survey Procedures for Seismic Risk Assessment in Urban Building Stocks (Level2) [6]

2. Preliminary Seismic Vulnerability Assessment of Existing RC Buildings in Turkey [3]

3. Preliminary Seismic Performance Assessment Procedure for Existing RC Buildings [7]

4. MVP Interaction Based Seismic Vulnerability Assessment of RC Buildings [2]

\section{Features}


These methods are the most common rapid assessment methods used to determine the earthquake performance of buildings.

Thanks to this method, earthquake performance scores of buildings can be found both in a short time and with high accurate result percentages.

In addition to SSM, these methods depend on the parameters that must be entered by entering the building. These parameters can be collocate as structural system element dimensions (column, shear wall, wall), ground floor area, building weight, concrete and reinforcement strengths. The processing steps of these methods are similar to SSA methods.

\subsection{EPA (Earthquake Performance Analysis) Computer Program}

A computer program, EPA, was developed in C \# programming language. Through this program, the earthquake performance scores of buildings can be calculated according to different rapid assessment method (RAM). The results of calculation can be compared and the appropriate RAM can be determined for the building. The buildings that has been evaluated can be displayed on the map. The program can also generate earthquake performance reports. The main application menus included in the EPA program are listed as parameter input screen, database screen, earthquake performance maps, earthquake performance graphs and earthquake performance reports.

\subsubsection{Parameters input screen}

Rapid assessment methods have different parameters and different calculation steps. EPA program provides a different parameter input screen for each method. The parameters of the building whose earthquake performance score will be determined are selected on the input screens and the earthquake performance status can be easily determined according to any rapid assessment method.

Figure 1. Sample parameter input screens for Street Survey (left) and Preliminary Assessment Methods (right)

\subsubsection{Database screen and earthquake performance maps}
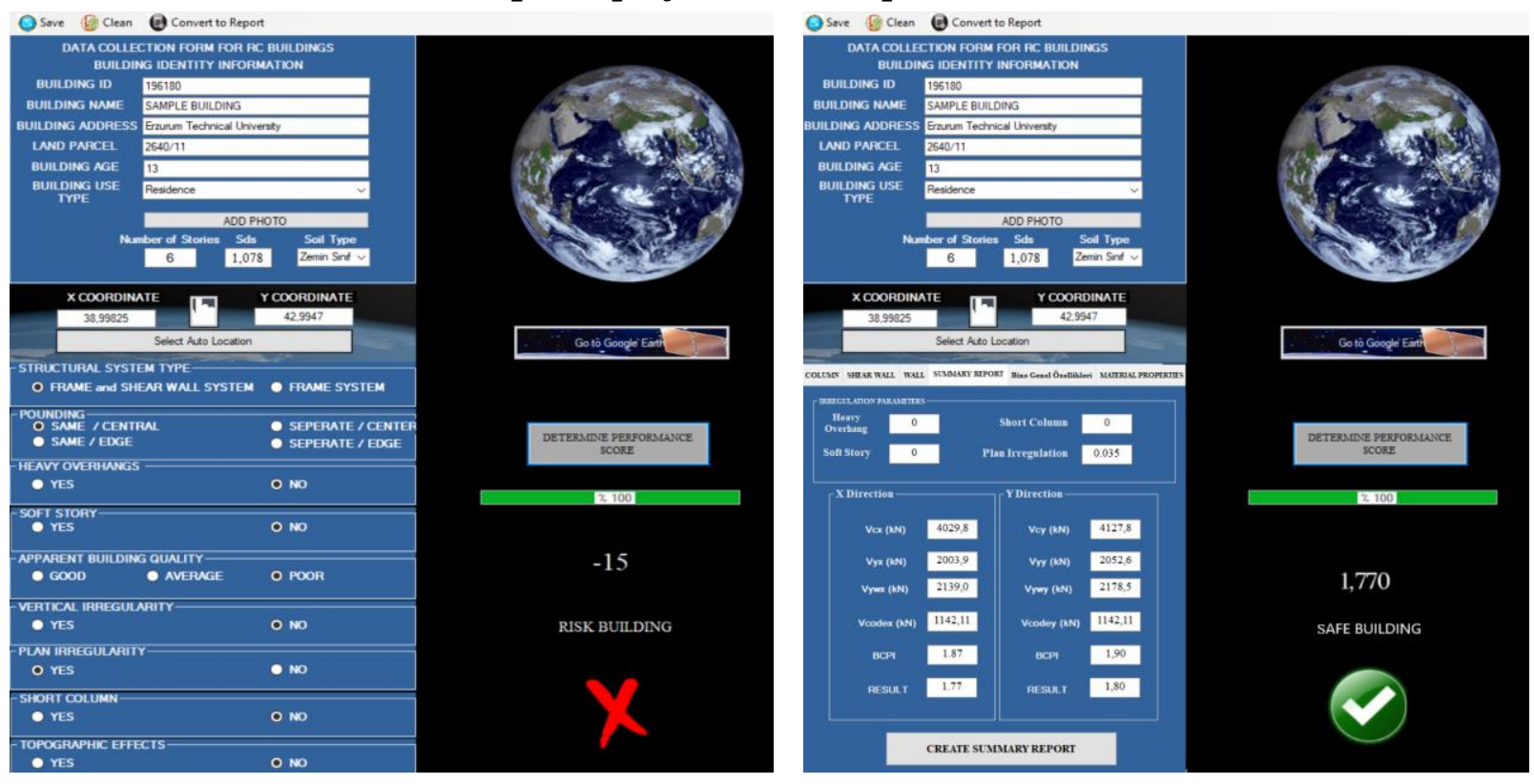
After the parameter information of the buildings whose earthquake performance is to be determined are defined to the EPA program, all information about the building is transferred to the database in the program through the save button on the parameter input screens. In the database, all saved buildings can be viewed. These buildings can be easily found or thousands of buildings can be classified by searching through number of stories, type of method used and building names. In addition, using the database screen, building earthquake performance results can be send to MS Excel, earthquake performance maps and earthquake performance graphs screens.

Any data (building) or any data set is transferred from the database to the application menu of earthquake performance maps. Earthquake performance maps are generated by using geographic coordinate data of buildings in the parameter input screens. It shows the earthquake performance status of buildings (Risky building, Safe building) on the map and the earthquake performance distributions of buildings on the map by assigning red point for risky buildings and green point for safe buildings.

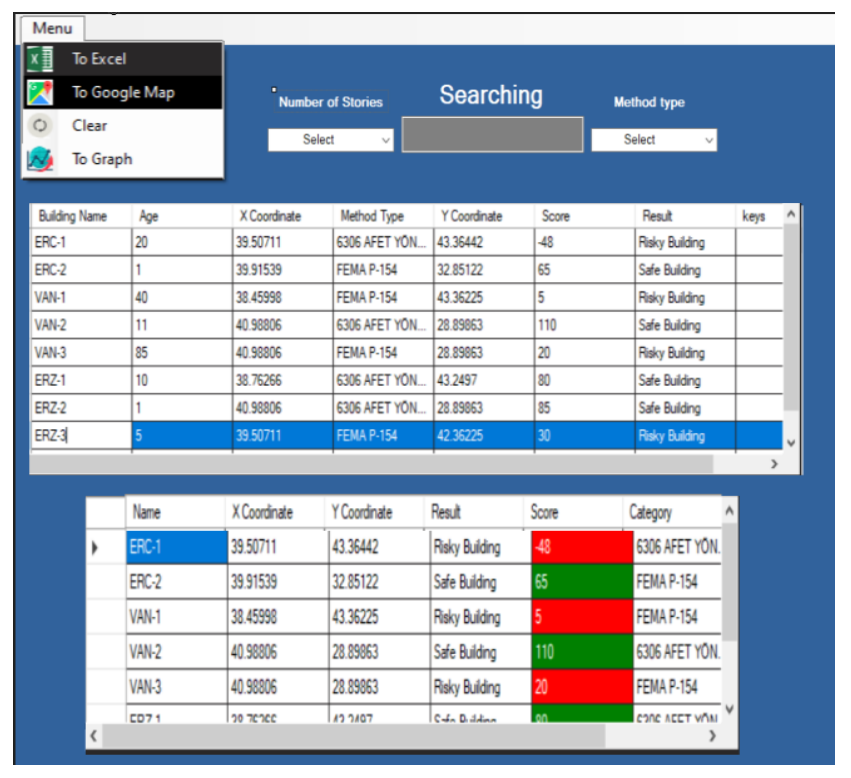

Figure 2. Database screen (left) and earthquake performance maps (right)

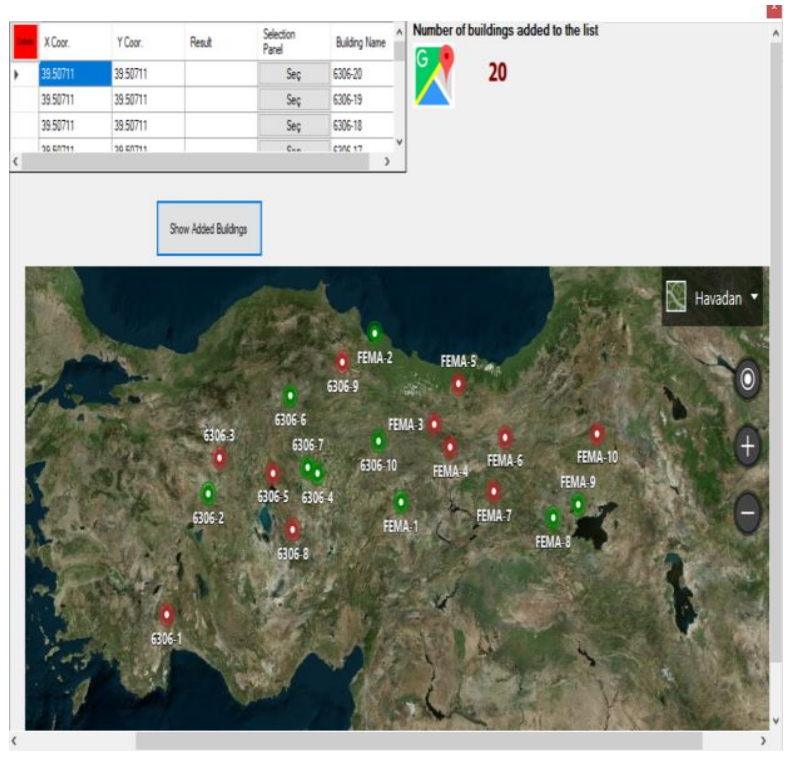

\subsubsection{Earthquake performance graphs and earthquake performance reports}

One of the main goals of this study is to find a rapid assessment method suitable for buildings. In order to that, it is necessary to select the method with the highest accuracy rate by evaluating the data sets examined in different rapid evaluation methods. Using earthquake performance graphs, the accuracy percentage of any data set to be analyzed can be easily found by all methods. Then, the most suitable method for the data set is selected by comparing the accuracy percentages of the methods.

The last application menu presented by the EPA program is the earthquake performance reports menu. This application menu generates reports in MS Word by using the parameters of the 
buildings that the earthquake performance evaluation had been made and the score equivalents of these parameters.
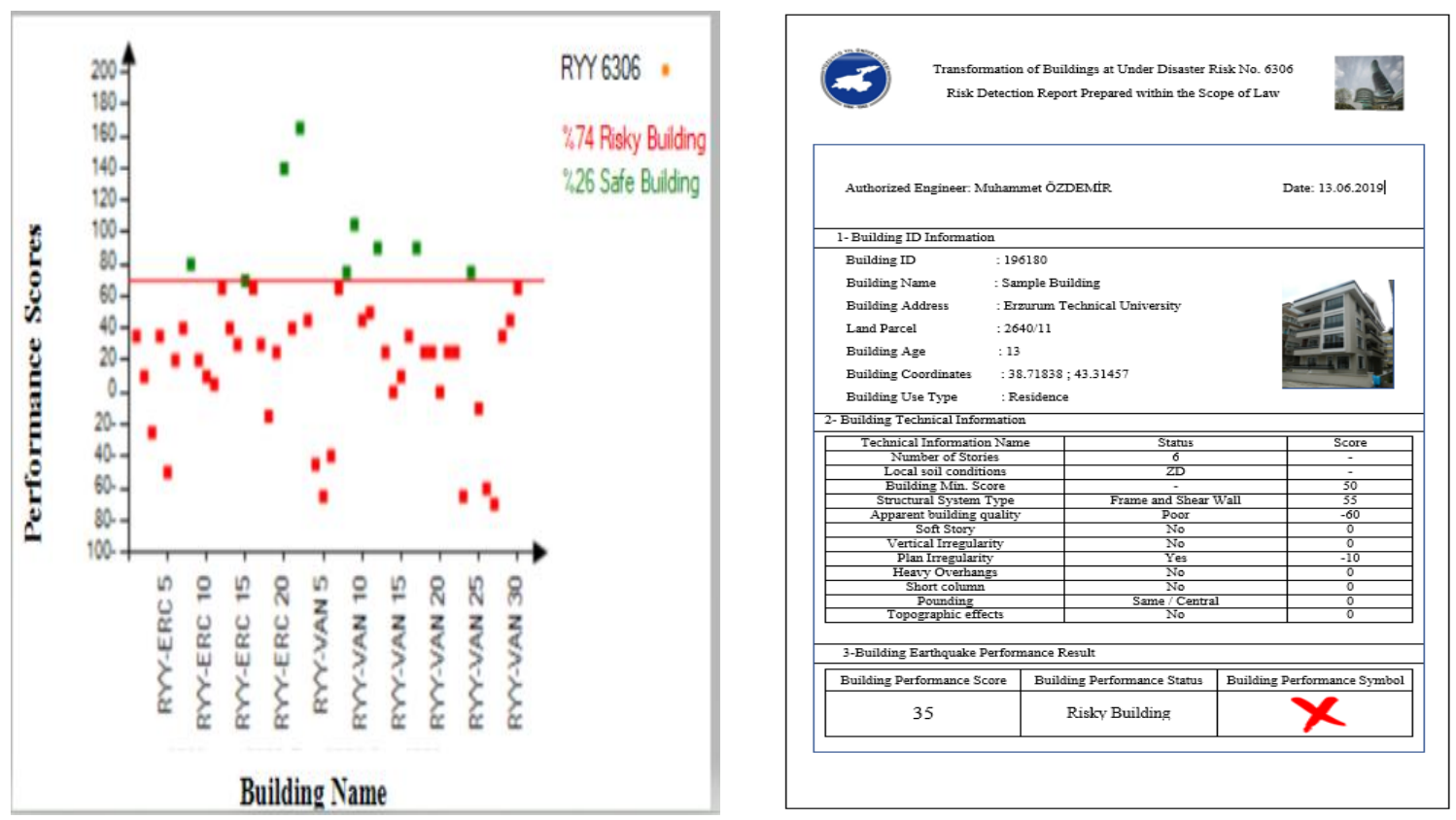

Figure 3. Earthquake performance graphs (left) and earthquake performance Report (right)

\section{Results}

Earthquake performance score and earthquake performance behavior of 50 buildings in the data set were determined according to 7 different rapid assessment methods using EPA program. Using the obtained performance scores, earthquake performance graphs showing the success percentages of the methods and earthquake performance maps of the related data set were created according to those methods.
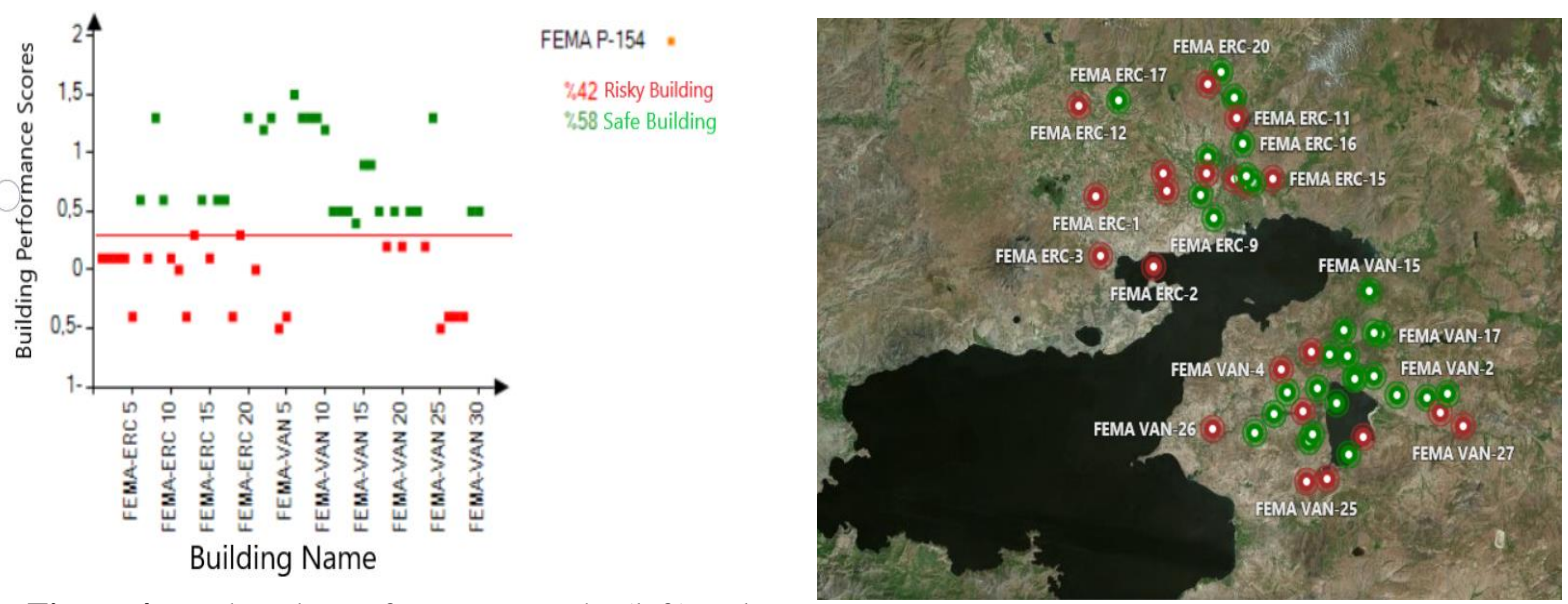

Figure 4. Earthquake performance graphs (left) and earthquake performance maps according to FEMA P-154 (right) 
According to the earthquake performance graph obtained by EPA program, $42 \%$ of the buildings in the data set were found to be risky and $58 \%$ as safe. Since all of the buildings in the dataset are collapsed or heavily damaged, the success rate of this method can be said to be $42 \%$. When the earthquake performance status of all buildings in the data set is evaluated according to the methods, the following table is revealed.

Table 2. Percentage of performance estimation on buildings in the data set of methods

\begin{tabular}{|c|c|c|c|c|c|c|c|}
\hline & \multicolumn{3}{|c|}{ Street Survey Methods } & \multicolumn{4}{|c|}{ Preliminary Assessment Methods } \\
\hline & $\begin{array}{l}6306 \\
\text { RYY }\end{array}$ & $\begin{array}{c}\text { FEMA } \\
\text { P-154 }\end{array}$ & $\begin{array}{c}\text { S\&Y Level } \\
1\end{array}$ & $\begin{array}{c}\text { S\&Y Level } \\
2\end{array}$ & Özcebe & Yakut & MVP \\
\hline $\begin{array}{c}\text { Right Guess } \\
(\%)\end{array}$ & 74 & 42 & 28 & 38 & 32 & 86 & 82 \\
\hline $\begin{array}{c}\text { Wrong Guess } \\
(\%)\end{array}$ & 26 & 58 & 72 & 62 & 68 & 14 & 18 \\
\hline
\end{tabular}

According to the obtained earthquake performance graphs, the percentage of buildings that are estimated correctly by all methods is $4 \%$. The percentage of buildings that the methods created with the data in Turkey (except FEMA P-154) accurately predicted is $22 \%$. All buildings that are correctly predicted have the majority of irregularities (plan irregularity, soft story, heavy overhang).

Among the street survey methods, the method that accurately predicts the earthquake performance behaviour of buildings at the highest rate (74\%) is the Regulation on Risk Structures (6306), which is officially used in Turkey. This rate is quite high for a street screening method and can be used to identify buildings with priority risk. Among the preliminary assessment methods, Yakut method is the method that accurately predicts the earthquake performance behaviour of buildings at the highest rate $(86 \%)$. It was also found that the methods using the concrete quality parameter had a much higher (approx. 40\%) accurate estimation percentage than the methods without using concrete quality parameter.

\section{Discussion}

As a result of the studies, two important questions have arisen. These are:

1. Are street screening methods and preliminary assessment methods safe enough to determine earthquake performance status of buildings? Which is the most reliable street screening and pre-assessment method?

2. How has changed the success percentage of the pre-assessment methods obtained using more parameters according to street screening methods? 

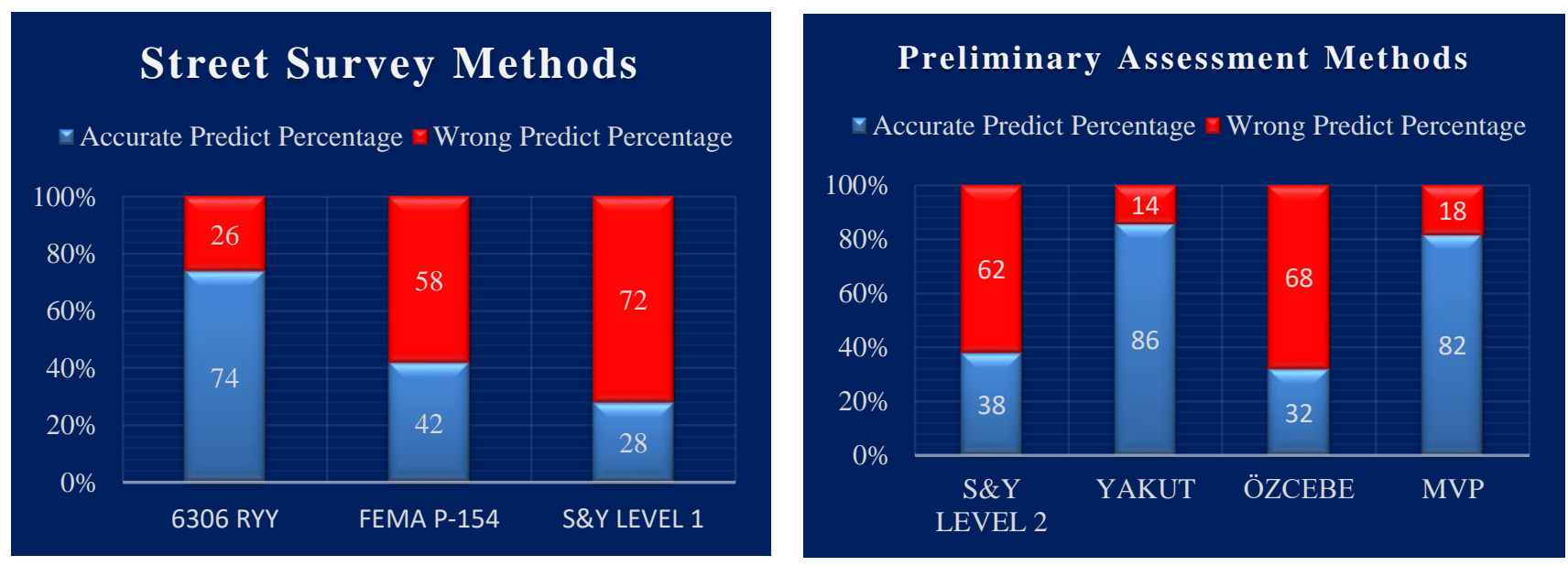

Figure 5. Percentage of accurate and inaccurate estimation on buildings in the data set of Street survey and Preliminary assessment methods

The most successful method of street survey methods was 6306 RYY with $74 \%$ accurate estimation. The most successful method of preliminary assessment with $86 \%$ accurate prediction was Yakut method. It was observed that earthquake performance behaviours of buildings can be estimated accurately by using rapid assessment methods and priority buildings (unsafe buildings) can be determined by creating earthquake risk maps.

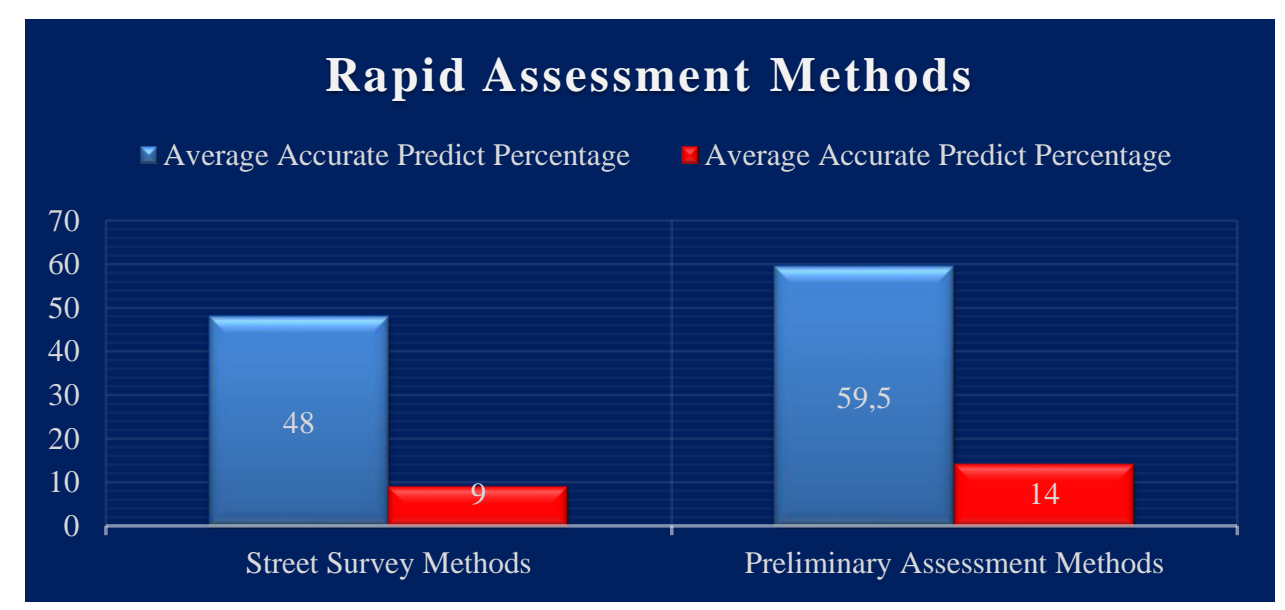

Figure 6. Average accurate estimation percentages and average parameter numbers of rapid evaluation methods.

According to Figure 6, preliminary assessment methods accurately predicted the earthquake performance behaviour of buildings by $24 \%$ higher using $55.5 \%$ more parameters than street survey methods. The parameters that make up the difference between the number of parameters and accuracy percentages of the methods can be listed as structural system element (column, shear wall) dimensions, concrete compressive strength, ground floor area, frame discontinuity and reinforcement detail information. 


\section{Conclusions}

The rapid assessment methods which are divided into street survey and preliminary assessment methods, can be used to determine the performance of buildings against earthquakes affects quickly and practically. The main purpose of these methods is to determine the buildings that need detailed analysis by determining the risk distribution of the buildings. Since these methods are created by using the data of a particular region, the success percentages of the methods in different regions may change. Therefore, in this study, the success rates of rapid evaluation methods were compared by using the data of buildings in Van city. The results obtained from this study can be listed as follows.

1. The determination of earthquake safety of existing structures constitutes technically the most critical part of earthquake mitigation strategies. Although there are various assessment methods developed for buildings, it is difficult to apply these methods to hundreds of thousands of buildings. For this reason, there is a need for the methods that provide fast and accurate results with less number of parameters. Using computer technology is making this process even much easier.

2. A sample data set was examined on the EPA program and the success rates of the methods were obtaied. According to these results, the most successful method of street survey methods is 6306 RYY with $74 \%$ accurate estimation and the most successful method with $86 \%$ accurate prediction percentage is Yakut.

3.Preliminary assessment methods used $55.5 \%$ more parameters than street survey methods to accurately predict earthquake performance behaviour of buildings at a rate of $24 \%$.

4. It was found that the most important parameter for the methods was the compressive strength of concrete and therefore it was recommended to use Test (Schmidt) hammer for accurate determination of this value.

5. It has been observed that earthquake performance behaviour of buildings can be predicted accurately by using rapid assessment methods and by using earthquake risk maps unsafe buildings can be determined easily and practically.

\section{Acknowledgements}

I would like to express my gratitude to the Scientific Research and Projects Coordination Unit (BAP) of the Yüzüncü Y1l University and to the university authorities for enabling this for supporting this study with the project number FYL-2019-8283.

\section{References}

[1] KRDAE, 2019. Boğaziçi University Kandilli Observatory and Earthquake Research Institute http://www.koeri.boun.edu.tr/simo/2/deprem-bilgileri/buyuk-depremler/. Date of Access: 05.04.2019.

[2] Erdil B., Ceylan H., "Comparison of Walk-Down Procedures in Evaluating Seismic Vulnerability of RC Buildings in Turkey", 3rd International Mediterranean Science and Engineering Congress (IMSEC 2018), Adana, Turkey, 24-26 Ekim 2018, pp.357-361 
[3] Özcebe, G., Yücemen, M. S., Aydoğan, V., Yakut, A. 2003. Preliminary Seismic Vulnerability Assessment of Existing Reinforced Concrete Buildings in Turkey. Seismic Assessment and Rehabilitiation of Existing Buildings, 29-42.

[4] FEMA 154, 2015. Rapid Visual Screening of Buildings for potential seismic hazards: A Handbook, Federal Emergency Management Agency, Washington DC, USA.

[5] TEC2018 (Turkish Earthquake Resistant Code) (2018) "Deprem Etkisi Altında Binaların Tasarımı İçin Esaslar (Specifications for Buildings to be Designed under Seismic Effect)”, Turkish Ministry of Public Works and Settlement, Ankara, Turkey.

[6]Sucuoglu H, Yazgan U. (2003). "Simple survey procedures for seismic risk assessment in urban building stocks.” In: Wasti ST, Özcebe G, editors. Seismic assessment and rehabilitation of existing buildings, earth and environmental sciences, Vol. 29. London:Kluwer Academic Publishers; 97118.

[7] Yakut A., (2004). "Preliminary Seismic Performance Assessment Procedure for Existing RC Buildings.” Engineering Structures, 26, 1447-1461. 